\title{
Accuracy of genotype imputation and genomic predictions in a two- generation farmed Atlantic salmon population using high-density and low- density SNP panels
}

\author{
Grazyella M. Yoshida ${ }^{\mathrm{a}, \mathrm{b}}$, Roberto Carvalheiro ${ }^{\mathrm{b}}$, Jean P. Lhorente ${ }^{\mathrm{c}}$, Katharina Correa ${ }^{\mathrm{c}}$, \\ René Figueroa $^{\mathrm{c}}$, Ross D. Houston ${ }^{\mathrm{d}}$, José M. Yáñez ${ }^{\mathrm{a}, \mathrm{c}, \mathrm{e}, *}$ \\ ${ }^{a}$ Facultad de Ciencias Veterinarias y Pecuarias, Universidad de Chile, Av. Santa Rosa 11735, La Pintana, Santiago 8820808, Chile \\ ${ }^{\mathrm{b}}$ School of Agricultural and Veterinarian Sciences, São Paulo State University (UNESP), Jaboticabal, Via de Acesso Prof. Paulo Donato Castellane, 14884-900 \\ Jaboticabal, Brazil \\ c Aquainnovo, Cardonal S/N, Puerto Montt, Chile \\ d The Roslin Institute and Royal (Dick) School of Veterinary Studies, University of Edinburgh, Midlothian EH25 9RG, UK \\ e Núcleo Milenio INVASAL, Concepción, Chile
}

\section{A R T I C L E I N F O}

\section{Keywords:}

Single nucleotide polymorphism

Salmo salar

Genomic selection

Genome-wide association studies

Cost-effectiveness

\begin{abstract}
A B S T R A C T
The objectives of this study were: (i) to assess genotype imputation accuracy in different scenarios using genomewide single nucleotide polymorphisms (SNP) data from a population comprising two generations of farmed Atlantic salmon and (ii) to assess the accuracy of genomic predictions for a quantitative trait (body weight) using the imputed genotypes. The pedigree consisted of 53 parents and 1069 offspring genotyped using a high-density SNP panel $(50 \mathrm{~K})$. Two groups were created: Group A: $90 \%$ of the offspring were included into training and $10 \%$ into validation sets; Group B: $10 \%$ of the offspring were included into training and $90 \%$ into validation sets. Different scenarios of available genotypic information from relatives were tested for the two groups previously described. Imputation was performed using three in silico low-density panels $(0.5,3$ and $6 \mathrm{~K})$ with all markers except the markers present on the low-density panel masked in the validation sets. The accuracy of genomic selection was tested using the scenarios that resulted in the best and the worst imputation accuracy for the three low density panels and were compared to accuracy obtained from pedigree-based best linear unbiased prediction (PBLUP) and genomic predictions using the $50 \mathrm{~K}$ SNP panel. In general, imputation accuracy ranged from 0.74 to 0.98 depending on scenario. For the best scenario with the highest number of animals in reference population (Group A), the accuracy of imputation ranged from 0.95 to 0.98 depending on the low-density panel used. For the best scenario with the lowest number of animals in reference population (Group B), the accuracy of imputation ranged from 0.94 to 0.98 depending on the low-density panel used. In general, the number of SNPs in the low-density panels had a greater influence on the accuracy of imputation than the size of the reference set. The accuracies of genomic predictions using imputed genotypes, ranging from 0.71 to 0.73 , outperformed PBLUP (0.66) and were identical or very similar to the use of all true genotype data (0.73). The high imputation and genomic prediction accuracy suggest that the imputation of genotypes from low density ( 0.5 to $3 \mathrm{~K})$ to high density $(50 \mathrm{~K})$ could be a cost-effective strategy for the feasibility of the practical implementation of genomic selection in Atlantic salmon.
\end{abstract}

\section{Introduction}

Recent advances in genotyping technology have facilitated the availability of high density genotyping panels, which can be used to accelerate the genetic progress of breeding programs by implementing genomic selection (Meuwissen et al., 2001). In fact, genomic predictions have shown to increase the accuracy of breeding values for several traits in salmonids (Bangera et al., 2017; Correa et al., 2017; Tsai et al., 2016, 2015; Vallejo et al., 2016, 2017; Yoshida et al., 2018). These methodologies are expected to be increasingly used in aquaculture species (Yáñez et al., 2015), especially for the improvement of traits which are difficult to measure in the selection candidates, such as disease resistance and carcass quality traits (Sonesson and Meuwissen, 2009; Yáñez and Martinez, 2010; Yáñez et al., 2014a). However, the

\footnotetext{
* Corresponding author at: Facultad de Ciencias Veterinarias y Pecuarias, Universidad de Chile, Av. Santa Rosa 11735, La Pintana, Santiago 8820808, Chile.

E-mail address: jmayanez@uchile.cl (J.M. Yáñez).
} 
cost associated with genotyping may represent a limiting factor for the use of genomic selection (VanRaden et al., 2011). An alternative for genomic applications would be to use a genotype imputation method for inferring missing genotypes that were not successfully called during genotyping, to infer the genotypes of ungenotyped individuals and/or to infer genotypes for individuals genotyped with a low-density panel using a reference population genotyped for a high-density marker panel (Sargolzaei et al., 2009).

The accuracy of imputation is influenced by several factors, including proportion of genotypes to be imputed (Zhang and Druet, 2010; Hickey et al., 2012), number of individuals in reference set (Druet et al., 2010; Zhang and Druet, 2010), relatedness between validation and reference set (Carvalheiro et al., 2014; Cleveland and Hickey, 2014), chromosomal position (Duarte et al., 2013; Hozé et al., 2013) and minor allele frequency (Badke et al., 2013).

Imputation could be used in Atlantic salmon breeding programs to decrease the costs of genotyping (Tsai et al., 2017). For instance, dense genotypes (e.g. $50 \mathrm{~K}$ ) from parents might be used to impute the missing genotypes from lower to higher-density in the offspring. However, low accuracies of imputation may be a limitation for the efficient use of lower-density panels. It is worth to mention that the cost for a lowdensity panel is considerably lower (e.g. USD \$ 5 to 15 for a 500 SNP panel) than the cost for a higher-density one (e.g. USD \$ 45 to 75 for a $50 \mathrm{~K}$ SNP panel, depending on the number of samples). Thus, assessing the accuracy of imputation in different scenarios is crucial to define an adequate genotyping strategy aiming at maximizing the genetic progress and minimizing the genotyping costs.

The objective of this study was to assess the accuracy of imputation and genomic predictions by testing different scenarios, using different densities of low-density SNP panels and number of animals in reference and validation set in a two-generation farmed Atlantic salmon population.

\section{Material and methods}

\subsection{Data}

The Atlantic salmon population used in the current study belongs to the 2006 and 2010 year-classes of the breeding program of Salmones Chaicas (Puerto Montt, Chile). The origin, management of the fish and genotyping are described in detail by Correa et al. (2015, 2016, 2017), Bangera et al. (2017) and Yáñez et al. (2013, 2014b, 2016). Briefly, the eggs of each full-sib family were incubated and reared in separate tanks from fecundation until tagging. An average number of 32 fish/family (ranging from 26 to 40) were tagged and distributed in six different tanks, with an average of 160 fish/family in total (ranging from 137 to 170). Fish were reared until they were an average of 25 months old and the trait body weight was recorded on each individual fish, with an average $331.2 \mathrm{~g}(\mathrm{SD}=121 \mathrm{~g})$.

Genomic DNA was extracted from fin clip samples from 53 parents (19 sires and 34 dams) and 1069 offspring, which were genotyped using a $50 \mathrm{~K}$ Affymetrix SNP array (Correa et al., 2015, 2016; Yáñez et al., 2016), hereafter called the high-density (HD) panel. Before imputation, genotypes and samples were filtered according to the following exclusion criteria: Hardy-Weinberg Disequilibrium (p-value $<1 \times 10^{-6}$ ), Minor Allele Frequency (MAF $<0.02$ ) and genotyping rate for SNP and samples $<0.95$. The SNPs and samples passed in the quality control were used for downstream analysis.

Three in silico low-density (LD) panels were constructed with SNP densities of 499 (LD0.5 K), 2928 (LD3 K), and 5878 (LD6 K). The SNPs from the LD panels were initially selected based on a proportional number of SNPs to chromosome size. Then SNPs were selected, based on approximate even spacing within each chromosome, highest MAF (within those which passed quality control) and having unique position when performing BLAST of the $71 \mathrm{pb}$ probes against the reference genome of Atlantic salmon (GenBank Accession no.

\section{GCA_000233375.4).}

\subsection{Imputation scenarios}

Two different groups of individuals were created, varying in the proportion of offspring in reference and validation set. For the "Group A", $90 \%$ of the offspring was used as reference and $10 \%$ as validation set. The "Group B" analyses were run using $10 \%$ of the offspring as reference and $90 \%$ as validation set. The assignment of the offspring to the reference and validation sets was at random, and five replicates were used each time.

Five scenarios per group were investigated, each of which defined the validation set for imputation. Scenario 1 (A1 and B1) involved genotyping of all the parents and offspring using the HD panel. Scenario 2 (A2 and B2) and Scenario 3 (A3 and B3) was the same as Scenario 1 except that genotypes for the dams and sires, respectively, were removed from the validation set. Scenario 4 (A4 and B4) and Scenario 5 (A5 and B5) comprised genotyping only the parents and the sibs with the HD panel, respectively. In each scenario, a pedigree of 1115 individuals was used for imputation, consisting of two generations of records for each genotyped animal. Imputation of genotypes was performed using the FImpute v2.2 software (Sargolzaei et al., 2014) and the accuracy of imputation was calculated as the correlation between true and imputed genotypes for the validation set.

\subsection{Genomic predictions}

Phenotypic data for body weight were available for animals from the 2010 year-class (Yoshida et al., 2017) and used to test the impact of imputation errors on the accuracy of genomic predictions. The accuracy of genomic predictions was evaluated only in Group B, because this is more proximate to realistic applications of genomic predictions using imputed genotype data. We used the imputed genotypes from the three low-density panels (0.5, 3 and $6 \mathrm{~K}$ ) for Scenario B1 and B5 (Group B) due the fact that these are the scenarios with the highest (B1) and lowest (B5) imputation accuracy. The breeding values (EBV) were predicted using both pedigree and genomic best linear unbiased prediction methods (PBLUP and GBLUP, respectively). The numerator (A) and genomic $(G)$ relationship matrices were used to account for the kinship between animals in PBLUP and GBLUP, respectively (VanRaden, 2008). The statistical model fitted was as follows:

$\mathrm{y}=\mathrm{X} \beta+\mathrm{Zg}+\mathrm{e}$

where $y$ is a vector of phenotypes (body weight), $\beta$ is a vector of fixed effects (tank and age), $g$ is a vector of additive genetic effects that follows a distribution $\sim \mathrm{N}\left(0, \mathrm{A \sigma}_{\mathrm{g}}{ }^{2}\right)$ or $\sim \mathrm{N}\left(0, \mathrm{G \sigma}_{\mathrm{g}}{ }^{2}\right)$, for PBLUP and GBLUP, respectively, where $\sigma_{\mathrm{g}}{ }^{2}$ is the additive genetic variance, and A and $G$ are the pedigree and genomic relationship matrices, respectively. $\mathrm{X}$ and $\mathrm{Z}$ are incidence matrices for fixed and additive effects, respectively, and $\mathrm{e}$ is the vector of random residual with a distribution $\sim \mathrm{N}$ $\left(0, \mathrm{I \sigma}_{\mathrm{e}}{ }^{2}\right)$, where $\sigma_{\mathrm{e}}^{2}$ is the residual variance and $\mathrm{I}$ is an identity matrix.

We used the BLUPF90 package (Misztal et al., 2016) to perform the genetic evaluations using pedigree and genomic information. Prediction accuracies were assessed using a five-fold cross validation scheme. Briefly, all phenotyped and genotyped animals $(n=963)$ were randomly divided into five validations sets $(20 \%$ of the dataset; mean $=192$ and $\mathrm{SD}=4$ animals), which were predicted one at a time by masking their phenotypes and using the remaining animals as a training set ( $80 \%$ of the dataset; $n=771$ and $S D=4$ animals) to estimate the marker effects. Prediction accuracies were calculated in the validation sets using the following formula:

$\mathrm{r}_{\mathrm{GEBV}, \mathrm{BV}}=\frac{\mathrm{r}_{\mathrm{GEBV}, \mathrm{y}}}{\mathrm{h}}$,

where $\mathrm{r}_{\mathrm{GEBV}}$, is the correlation between the EBV or GEBV of a given model (predicted for the validation set using information from the 
Table 1

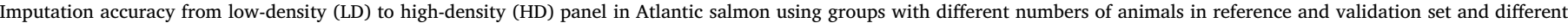
scenarios of available genotypic information.

\begin{tabular}{|c|c|c|c|c|c|c|c|c|}
\hline \multirow[t]{2}{*}{ Scenario } & \multicolumn{3}{|c|}{ Reference } & \multirow[t]{2}{*}{ Size } & \multirow[t]{2}{*}{ Validation $^{\mathrm{b}}$} & \multirow{2}{*}{$\begin{array}{l}\text { LD0.5 K } \\
\text { Mean }\end{array}$} & \multirow{2}{*}{$\frac{\text { LD3 K }}{\text { Mean }}$} & \multirow{2}{*}{$\begin{array}{l}\text { LD6 K } \\
\text { Mean }\end{array}$} \\
\hline & $\begin{array}{l}\text { Sires } \\
\mathrm{n}=19\end{array}$ & $\begin{array}{l}\text { Dams } \\
\mathrm{n}=34\end{array}$ & $\operatorname{Sibs}^{\mathrm{a}}$ & & & & & \\
\hline \multicolumn{9}{|l|}{ Group A } \\
\hline $\mathrm{A} 1$ & HD & HD & HD & 1015 & LD & 0.948 & 0.980 & 0.983 \\
\hline A2 & $\mathrm{HD}$ & - & HD & 981 & LD & 0.863 & 0.967 & 0.973 \\
\hline A3 & - & HD & HD & 996 & LD & 0.864 & 0.962 & 0.971 \\
\hline A4 & - & - & HD & 962 & LD & 0.851 & 0.976 & 0.982 \\
\hline A5 & HD & HD & - & 53 & LD & 0.829 & 0.942 & 0.951 \\
\hline \multicolumn{9}{|l|}{ Group B } \\
\hline B1 & HD & HD & HD & 159 & LD & 0.940 & 0.974 & 0.977 \\
\hline B2 & HD & - & HD & 125 & LD & 0.820 & 0.944 & 0.955 \\
\hline B3 & - & HD & HD & 140 & LD & 0.786 & 0.932 & 0.948 \\
\hline B4 & - & - & HD & 106 & LD & 0.737 & 0.936 & 0.950 \\
\hline B5 & $\mathrm{HD}$ & HD & - & 53 & LD & 0.736 & 0.943 & 0.952 \\
\hline
\end{tabular}

a 963 and 106 offsprings with HD in reference set for Group A and B, respectively.

b 106 and 963 offsprings with LD in the validation set for Group A and B, respectively.

training set) and the phenotypic record, while $h$ is the square root of the pedigree-based estimate of heritability.

\section{Results}

\subsection{Accuracy of genotype imputation}

A total of 37,259 SNPs and 1122 samples passed the filtering criteria. We observed that genotype imputation accuracy increased with increasing marker density of the LD genotyping panels and with increasing proportions of close ancestors having high-density genotypes (Table 1). For all cases, imputation accuracy decreased with reduced marker density going from $6 \mathrm{~K}$ to $0.5 \mathrm{~K}$ (Table 1 ). The largest increase in imputation accuracy occurred when increasing SNP density from $0.5 \mathrm{~K}$ to $3 \mathrm{~K}$ (rather than from $3 \mathrm{~K}$ to $6 \mathrm{~K}$ ), indicating that the $3 \mathrm{~K}$ panel would provide highly accurate imputed genotypes, with similar imputation accuracies than the $6 \mathrm{~K}$ panel.

The lower number of animals in Group B reference set resulted in lower imputation accuracies compared to Group A, with the difference being more evident when fewer number of ancestors were used as reference set (Scenarios A1 vs A5 and B1 vs B5). In addition, the largest changes in accuracy between genotyping scenarios were observed for the SNPs chips with the lower density, LD0.5 K. In the case where genotyping both parents is not possible, we observed that the sire's genotype information (B2) is more important to obtain better imputations accuracies than just the dam's genotype information (B3) for Group B (Table 1). For both Groups A and B, the HD genotype information of both parents is more critical to achieve high imputation accuracy than only sibs' information, especially for LD0.5 K panels, but this relevance decreased with increasing SNP density of the LD panel.

Figs. 1 and 2 show imputation accuracy in chromosome 1 for Group A and B, respectively, for Scenario 1 and 5 (for all chromosomes see Supplementary material). Imputation accuracy was not consistent across the chromosomes and depended on physical position of imputed SNP and location of low-density SNP. The largest differences were observed for LD0.5 K panel in both Group A and B (Figs. 1 and 2, respectively). The imputation accuracy decreased greatly at chromosomal ends, especially for LD0.5 K panel. Increasing SNP density of the LD panel form $0.5 \mathrm{~K}$ to $3 \mathrm{~K}$ or $6 \mathrm{~K}$ substantially improved imputation accuracy at chromosome ends.

\subsection{Accuracy of genomic predictions using imputed genotypes}

The genomic prediction accuracy using imputed genotypes, were identical or very similar among the scenarios and low-density panel tested compared to the use of the real $50 \mathrm{~K}$ SNP genotypes (Fig. 3). As expected, the lowest genomic prediction accuracy was observed for the scenario and SNP panel with lowest imputation accuracy (i.e. Scenario B5 and LD0.5 K panel), which resulted in an accuracy slightly lower compared to the use of the real $50 \mathrm{~K}$ SNP panel ( 0.71 vs 0.73 , respectively). All other SNP panel densities from Scenario B1 and B5 resulted in genomic prediction accuracy higher than pedigree-based method (0.66) and identical to the use of a $50 \mathrm{~K}$ SNP panel. The prediction accuracy improved $11 \%$ and $8 \%$ for the best and worst Scenario (Scenario $\mathrm{B} 1$ and Scenario $\mathrm{B} 5 / \mathrm{LD} 0.5 \mathrm{~K}$, respectively) compared to the pedigree-based method.

\section{Discussion}

The imputation method used by FImpute is based on the concept that close relatives share long haplotypes and the imputation is carried out using overlapping sliding windows starting with long haplotypes and moving towards short haplotypes (Sargolzaei et al., 2014). According to previous studies, the method results in high imputation accuracy when close relatives of targeted individuals are present in the reference group and computing requirements are considerably lower than other software used for imputation (Carvalheiro et al., 2014; Larmer et al., 2014; Sargolzaei et al., 2014).

Here we found that, in general, the imputation accuracy decreased in a non-linear manner from $6 \mathrm{~K}$ to $0.5 \mathrm{~K}$, which is in accordance with the results obtained by Habier et al. (2009) and Hickey et al. (2012), who also observed that the higher the proportion of genotypes to be imputed, the lower is the imputation accuracy. This can be due to the fact that panels with few SNPs could present low linkage and linkage disequilibrium between the markers, increasing imputation errors. The similarly high imputation accuracy between 3 and $6 \mathrm{~K}$ SNP panels are in agreement with studies carried out with pigs (Duarte et al., 2013; Cleveland and Hickey, 2014), cattle (Druet et al., 2010; Zhang and Druet, 2010; Carvalheiro et al., 2014), sheep (Hayes et al., 2012) and Atlantic salmon (Kijas et al., 2016; Tsai et al., 2017). The 500 SNP panel showed the lowest imputation accuracies for the different scenarios tested; however, it is most likely to be considerably much cheaper than any $3 \mathrm{~K}$ and $6 \mathrm{~K}$ SNP panel, thus cost-effectiveness must be carefully evaluated, taking genotyping cost and imputation and genomic prediction accuracies into account.

Based on the results from different scenarios for Group A and B, the effect of the number of genotyped individuals with the reference SNP panel seems to be smaller than the influence of the number of SNPs in 


$$
\frac{E}{E}
$$




$$
\begin{aligned}
& E E \\
& E E \\
& {[E}
\end{aligned}
$$




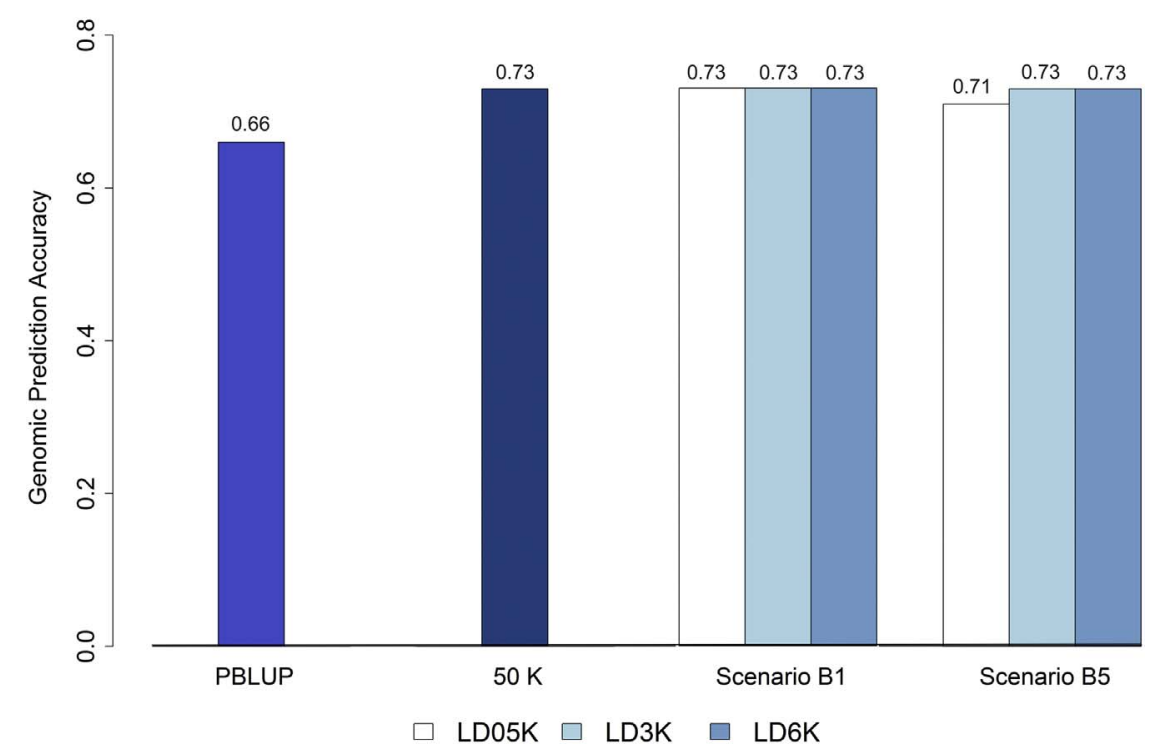

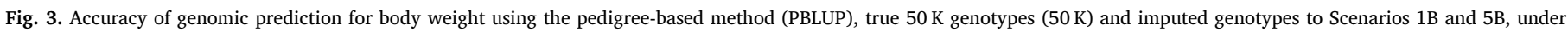
different low-density panels $(0.5,3$ and $6 \mathrm{~K})$ for Salmon salar.

LD panel. The size of the reference population should be large enough and not be a major factor influencing imputation accuracy using small panels for a portion of the population. The main benefit of increasing number of reference individuals will be obtained through increasing genotyping of highly related individuals between target and reference individuals (Zhang and Druet, 2010).

Here we also found that imputation accuracy was higher by using HD genotypes from sires instead of HD genotypes from dams, when HD genotypes from only one parent were available. These differences are more evident for Group B. The large paternal full-sib sample structure ( $\sim 56$ offspring per sire) could contribute for a better haplotype reconstruction than just using maternal full-sib samples $(\sim 31$ offspring per dam). In addition, Gilbey et al. (2004); Lien et al. (2011) and Moen et al. (2004) suggested that there are large differences in recombination rates between sexes in Salmo salar, in a ratio ranging from 1.38:1 to 8.26:1 (female:male). A slow decay in linkage disequilibrium could be a consequence of low recombination rates in males which resulted in higher accuracy of imputation when compared to females.

The lower accuracy found around the beginning and end of the chromosomes could be due to the fact the recombination is known to be higher around the telomeres, which would decrease the precision of haplotype reconstruction and imputation accuracy (Chowdhury et al., 2009; Tortereau et al., 2012). Low imputation accuracies in centromere regions might be attributed to incorrect order of markers on the reference genome in regions difficult to assemble.

In some chromosome regions, a notably low imputation accuracy is evident (e.g. chromosome 8 and 17 in Scenario 5, Supplementary material 1D and 2D). This suggests errors in the SNP position given by an incorrect anchoring of these markers to the genome or errors in the current reference genome assembly. These regions had markers with very low levels of linkage disequilibrium with neighboring markers, resulting in very low imputation accuracies (Carvalheiro et al., 2014; Druet et al., 2010). Sun et al. (2012) observed that imputation accuracy was positively associated with chromosome size due to the fact that longer chromosomes harbour more markers, and hence providing more information for inferring unknown haplotypes and imputing missing genotypes. In longer chromosomes, the problem of low imputation accuracy at the beginning and end of the chromosomes are relatively less important than in shorter chromosomes.

The imputation accuracy improved when Erbe et al. (2012) remapped the SNPs with high errors rates using linkage disequilibrium. However, they still found poorly imputed SNPs after remapping, suggesting that recombination hot spots or regions on the panel with lower SNP density, could result in the high imputation error rates for some SNPs (Hozé et al., 2013). In our study, some of the markers with low imputation accuracy were removed before imputation $(\sim 3 \%$ of all SNPs in Scenario A5 and B5) to try to improve the accuracy. Only a marginal gain was observed, ranging, for example, from 0.83 to 0.86 and 0.74 to 0.77 for LD0.5 K panel in Scenario A5 and B5, respectively, which were the scenarios with the highest accuracy gain. This result is most likely due to the small proportion of discarded markers. However, for genome wide association studies could be preferable to treat these markers with high error rates with caution, to avoid the negative impact of imputation errors in the QTL detection.

To test the impact of genotype imputation errors in genome-enabled selection methods, we estimated the accuracy of genomic predictions for body weight using the worst and the best scenarios for Group B, based on imputation accuracy. The present results are in accordance to previous studies carried out in aquaculture (Tsai et al., 2017) and livestock species (Berry and Kearney, 2011; Erbe et al., 2012), in which genomic prediction accuracies using imputed genotypes were always higher than those obtained using pedigree-based BLUP and not much lower than using HD genotypes.

The present study showed that the genomic prediction accuracy using imputed genotypes, for all densities of LD SNP panels, outperformed the pedigree-based method in the best and the worst scenarios of imputation accuracy (B1 and B5). In addition, the genomic prediction accuracies when genotyping both parents and a proportion of the progeny (10\%) with the HD panel (Scenario B1), along the three low density panels used in the validation population, were identical to the accuracies obtained by using the $50 \mathrm{~K}$ SNP panel. The same result was observed for LD panels of $3 \mathrm{~K}$ and $6 \mathrm{~K}$ when both parents were genotyped with the HD panel (Scenario B5). As expected, the lowest genomic prediction accuracy was observed for the scenario and SNP panel with lowest imputation accuracy (i.e. Scenario B5 and LD0.5 K panel), which resulted in an accuracy slightly lower compared to the use of the real $50 \mathrm{~K}$ SNP panel ( $0.71 \mathrm{vs} 0.73$, respectively). These results indicate that the use of an appropriate genotyping strategy combining the genotyping of both parents and a percentage $(10 \%)$ of the total progeny using a HD panel and a greater proportion (90\%) of the progeny with a LD panel (500 SNPs), represents an alternative to reach similar accuracy to that achieved by genotyping all animals with a HD panel. These results may be used to plan genotyping strategies to reduce the costs for the practical implementation of genomic selection in 
Atlantic salmon.

Supplementary data to this article can be found online at https:// doi.org/10.1016/j.aquaculture.2018.03.004.

\section{Acknowledgments}

This project has been partially funded by the grant a RCUKCONICYT, Research Partnership Call (MR/N026144/1 and BB/ N024044/1). GMY acknowledge Fundação de Amparo à Pesquisa do Estado de São Paulo (FAPESP processes numbers 2014/20626-4 and 2015/25232-7) for Doctoral fellowship. RC acknowledge for CNPq fellowship (process 308636/2014-7). RDH acknowledges support from BBSRC Institute Strategic Funding Grants to The Roslin Institute (BB/ J004235/1, BB/J004324/1). JMY also acknowledges support from Núcleo Milenio INVASAL from Iniciativa Científica Milenio (Ministerio de Economía, Fomento y Turismo, Gobierno de Chile).

\section{References}

Badke, Y.M., Bates, R.O., Ernst, C.W., Schwab, C., Fix, J., Van Tassell, C.P., Steibel, J.P., 2013. Methods of tagSNP selection and other variables affecting imputation accuracy in swine. BMC Genet. 14, 8. http://dx.doi.org/10.1186/1471-2156-14-8.

Bangera, R., Correa, K., Lhorente, J.P., Figueroa, R., Yáñez, J.M., 2017. Genomic predictions can accelerate selection for resistance against Piscirickettsia salmonis in Atlantic salmon (Salmo salar). BMC Genomics 18, 121. http://dx.doi.org/10.1186/ s12864-017-3487-y.

Berry, D.P., Kearney, J.F., 2011. Imputation of genotypes from low- to high-density genotyping platforms and implications for genomic selection. Animal 5, 1162-1169. http://dx.doi.org/10.1017/S1751731111000309.

Carvalheiro, R., Boison, S.A., Neves, H.H.R., Sargolzaei, M., Schenkel, F.S., Utsunomiya, Y.T., Maria, A., Brien, P.O., Sölkner, J., Mcewan, J.C., Van Tassell, C.P., Sonstegard, T.S., Garcia, J.F., 2014. Accuracy of genotype imputation in Nelore cattle. Genet. Sel. Evol. 46, 1-11.

Chowdhury, R., Bois, P.R.J., Feingold, E., Sherman, S.L., Cheung, V.G., Broman, K., Murray, J., Sheffield, V., White, R., Weber, J., Cheung, V., Burdick, J., Hirschmann, D., Morley, M., Coop, G., Wen, X., Ober, C., Pritchard, J., Przeworski, M., Shifman, S., Bell, J., Copley, R., Taylor, M., Williams, R., Petkov, P., Broman, K., Szatkiewicz, J., Paigen, K., Hassold, T., Hall, H., Hunt, P., Lamb, N., Sherman, S., Hassold, T., Henderson, K., Kee, K., Maleki, S., Santini, P., Keeney, S., Keeney, S., Neale, M., Stahl, F., Foss, H., Stefansson, H., Helgason, A., Thorleifsson, G., Steinthorsdottir, V., Masson, G., Kong, A., Thorleifsson, G., Stefansson, H., Masson, G., Helgason, A., Weiss, L., Shen, Y., Korn, J., Arking, D., Miller, D., Dawber, T., Meadors Jr., G., F.M., Kong, A., Gudbjartsson, D., Sainz, J., Jonsdottir, G., Gudjonsson, S., Su, A., Cooke, M., Ching, K., Hakak, Y., Walker, J., Barrett, T., Troup, D., Wilhite, S., Ledoux, P., Rudnev, D., Lamprecht, G., Seidler, U., Lassalle, B., Bastos, H., Louis, J., Riou, L., Testart, J., Bastos, H., Lassalle, B., Chicheportiche, A., Riou, L., Testart, J., Purcell, S., Neale, B., Todd-Brown, K., Thomas, L., Ferreira, M., Li, Y., Abecasis, G., 2009. Genetic analysis of variation in human meiotic recombination. PLoS Genet. e1000648, 5. http://dx.doi.org/10.1371/journal.pgen.1000648.

Cleveland, M.A., Hickey, J.M., 2014. Practical implementation of cost-effective genomic selection in commercial pig breeding using imputation. J. Anim. Sci. 91, 3583-3592. http://dx.doi.org/10.2527/jas2013-6270.

Correa, K., Lhorente, J.P., López, M.E., Bassini, L., Naswa, S., Deeb, N., Di Genova, A., Maass, A., Davidson, W.S., Yáñez, J.M., 2015. Genome-wide association analysis reveals loci associated with resistance against Piscirickettsia salmonis in two Atlantic salmon (Salmo salar L.) chromosomes. BMC Genomics 16, 854. http://dx.doi.org/10. 1186/s12864-015-2038-7.

Correa, K., Lhorente, J.P., Bassini, L., López, M.E., Di Génova, A., Maass, A., Davidson, W.S., Yáñez, J.M., 2016. Genome wide association study for resistance to Caligus rogercresseyi in Atlantic salmon (Salmo salar L.) using a $50 \mathrm{~K}$ SNP genotyping array. Aquaculture. http://dx.doi.org/10.1016/j.aquaculture.2016.04.008.

Correa, K., Bangera, R., Figueroa, R., Lhorente, J.P., Yáñez, J.M., 2017. The use of genomic information increases the accuracy of breeding value predictions for sea louse (Caligus rogercresseyi) resistance in Atlantic salmon (Salmo salar). Genet. Sel. Evol. 49, 15. http://dx.doi.org/10.1186/s12711-017-0291-8.

Druet, T., Schrooten, C., de Roos, A.P.W., 2010. Imputation of genotypes from different single nucleotide polymorphism panels in dairy cattle. J. Dairy Sci. 93, 5443-5454. http://dx.doi.org/10.3168/jds.2010-3255.

Duarte, J.L.G., Bates, R.O., Ernst, C.W., Raney, N.E., Cantet, R.J.C., Steibel, J.P., 2013. Genotype imputation accuracy in a F2 pig population using high density and low density SNP panels. BMC Genet. 14, 38.

Erbe, M., Hayes, B.J., Matukumalli, L.K., Goswami, S., Bowman, P.J., Reich, C.M., Mason, B.A., Goddard, M.E., 2012. Improving accuracy of genomic predictions within and between dairy cattle breeds with imputed high-density single nucleotide polymorphism panels. J. Dairy Sci. 95, 4114-4129. http://dx.doi.org/10.3168/jds.2011 5019.

Gilbey, J., Verspoor, E., McLay, A., Houlihan, D., 2004. A microsatellite linkage map for Atlantic salmon (Salmo salar). Anim. Genet. 35, 98-105.

Habier, D., Fernando, R., Dekkers, J., 2009. Genomic selection using low-density marker panels. Genetics 182, 343-353. http://dx.doi.org/10.1534/genetics.108.100289.
Hayes, B.J., Bowman, P.J., Daetwyler, H.D., Kijas, J.W., van der Werf, J.H.J., 2012. Accuracy of genotype imputation in sheep breeds. Anim. Genet. 43, 72-80. http://dx. doi.org/10.1111/j.1365-2052.2011.02208.x.

Hickey, J.M., Crossa, J., Babu, R., de los Campos, G., 2012. Factors affecting the accuracy of genotype imputation in populations from several maize breeding programs. Crop Sci. 52, 654. http://dx.doi.org/10.2135/cropsci2011.07.0358.

Hozé, C., Fouilloux, M.-N., Venot, E., Guillaume, F., Dassonneville, R., Fritz, S., Ducrocq, V., Phocas, F., Boichard, D., Croiseau, P., 2013. High-density marker imputation accuracy in sixteen French cattle breeds. Genet. Sel. Evol. 45, 33. http://dx.doi.org/ 10.1186/1297-9686-45-33.

Kijas, J., Elliot, N., Kube, P., Evans, B., Botwright, N., King, H., Primmer, C.R., Verbyla, K., 2016. Diversity and linkage disequilibrium in farmed Tasmanian Atlantic salmon. Anim. Genet. http://dx.doi.org/10.1111/age.12513.

Larmer, S.G., Sargolzaei, M., Schenkel, F.S., 2014. Extent of linkage disequilibrium, consistency of gametic phase, and imputation accuracy within and across Canadian dairy breeds. J. Dairy Sci. 97, 3128-3141. http://dx.doi.org/10.3168/JDS.20136826.

Lien, S., Gidskehaug, L., Moen, T., Hayes, B.J., Berg, P.R., Davidson, W.S., Omholt, S.W., Kent, M.P., 2011. A dense SNP-based linkage map for Atlantic salmon (Salmo salar) reveals extended chromosome homeologies and striking differences in sex-specific recombination patterns. BMC Genomics 12, 615.

Meuwissen, T.H.E., Hayes, B.J., Goddard, M.E., 2001. Prediction of total genetic value using genome-wide dense marker maps. Genetics 157, 1819-1829.

Misztal, I., Tsuruta, S., Lourenco, D., Masuda, Y., Aguilar, I., Legarra, A., 2016. Manual for BLUPF90 Family of Programs. University of Georgia, Athens.

Moen, T., Hoyheim, B., Munck, H., Gomez-Raya, L., 2004. A linkage map of Atlantic salmon (Salmo salar) reveals an uncommonly large difference in recombination rate between the sexes. Anim. Genet. 35, 81-92.

Sargolzaei, M., Chesnais, J.P., Schenkel, F.S., 2009. Accuracy of a family-based genotype imputation algorithm. In: GEB Open Industry Session, Saint-Hyacynthe Quebec, Canada, Accessed Jun. 1, 2017. www.cdn.ca/Articles/GEBAPR2010/Mehdi\%20$\% 20$ Accuracy $\% 20$ of $\% 20$ Family-Based\%20Imputing.pdf.

Sargolzaei, M., Chesnais, J.P., Schenkel, F.S., 2014. A new approach for efficient genotype imputation using information from relatives. BMC Genomics 15, 478. http://dx.doi. org/10.1186/1471-2164-15-478.

Sonesson, A.K., Meuwissen, T.H.E., 2009. Testing strategies for genomic selection in aquaculture breeding programs. Genet. Sel. Evol. 41, 37. http://dx.doi.org/10.1186/ 1297-9686-41-37.

Sun, C., Wu, X.-L., Weigel, K.A., Rosa, G.J.M., Bauck, S., Woodward, B.W., Schnabel, R.D., Taylor, J.F., Gianola, D., 2012. An ensemble-based approach to imputation of moderate-density genotypes for genomic selection with application to Angus cattle. Genet. Res. (Camb.) 94, 133-150. http://dx.doi.org/10.1017/S001667231200033X.

Tortereau, F., Servin, B., Frantz, L., Megens, H.-J., Milan, D., Rohrer, G., Wiedmann, R., Beever, J., Archibald, A.L., Schook, L.B., Groenen, M.A., 2012. A high density recombination map of the pig reveals a correlation between sex-specific recombination and GC content. BMC Genomics 13, 586. http://dx.doi.org/10.1186/1471-2164-13586.

Tsai, H.Y., Hamilton, A., Tinch, A.E., Guy, D.R., Gharbi, K., Stear, M.J., Matika, O., Bishop, S.C., Houston, R.D., 2015. Genome wide association and genomic prediction for growth traits in juvenile farmed Atlantic salmon using a high density SNP array. BMC Genomics 1-9. http://dx.doi.org/10.1186/s12864-015-2117-9.

Tsai, H.-Y., Hamilton, A., Tinch, A.E., Guy, D.R., Bron, J.E., Taggart, J.B., Gharbi, K., Stear, M., Matika, O., Pong-Wong, R., Bishop, S.C., Houston, R.D., 2016. Genomic prediction of host resistance to sea lice in farmed Atlantic salmon populations. Genet. Sel. Evol. 48, 47. http://dx.doi.org/10.1186/s12711-016-0226-9.

Tsai, H.-Y., Matika, O., Edwards, S.M., Antolín-Sánchez, R., Hamilton, A., Guy, D.R., Tinch, A.E., Gharbi, K., Stear, M.J., Taggart, J.B., Bron, J.E., Hickey, J.M., Houston, R.D., 2017. Genotype imputation to improve the cost-efficiency of genomic selection in farmed Atlantic salmon. G3 Genes Genomes Genet. 7.

Vallejo, R.L., Leeds, T.D., Fragomeni, B.O., Gao, G., Hernandez, A.G., Misztal, I., Welch, T.J., Wiens, G.D., Palti, Y., 2016. Evaluation of genome-enabled selection for bacterial cold water disease resistance using progeny performance data in rainbow trout: insights on genotyping methods and genomic prediction models. Front. Genet. 7, 1-13. http://dx.doi.org/10.3389/fgene.2016.00096.

Vallejo, R.L., Leeds, T.D., Gao, G., Parsons, J.E., Martin, K.E., Evenhuis, J.P., Fragomeni, B.O., Wiens, G.D., Palti, Y., 2017. Genomic selection models double the accuracy of predicted breeding values for bacterial cold water disease resistance compared to a traditional pedigree-based model in rainbow trout aquaculture. Genet. Sel. Evol. 49, 17. http://dx.doi.org/10.1186/s12711-017-0293-6.

VanRaden, P.M., 2008. Efficient methods to compute genomic predictions. J. Dairy Sci. 91, 4414-4423. http://dx.doi.org/10.3168/jds.2007-0980.

VanRaden, P.M., O'Connell, J.R., Wiggans, G.R., Weigel, K.A., Calus, M., Meuwissen, T., Roose, A., Veerkamp, R., Solberg, T., Sonesson, A., Woolliams, J., VanRaden, P., Van Tassell, C., Wiggans, G., Sonstegard, T., Schnabel, R., Taylor, J., Schenkel, F., Wiggans, G., VanRaden, P., Bacheller, L., Tooker, M., Hutchison, J., Cooper, T., Sonstegard, T., Weigel, K., de los Campos, G., González-Recio, O., Naya, H., Wu, X., Long, N., Rosa, G., Gianola, D., Weigel, K., de los Campos, G., Vazquez, A., Rosa, G., Gianola, D., Van Tassell, C., VanRaden, P., Wiggans, G., Van Tassell, C., Sonstegard, T., Schenkel, F., Harris, B., Johnson, D., Li, Y., Willer, C., Sanna, S., Abecasis, G., Druet, T., Schrooten, C., de Roos, A., Lund, M., de Roos, A., de Vries, A., Druet, T., Ducrocq, V., Fritz, S., Guillaume, F., Guldbrandtsen, B., Liu, Z., Reents, R., Schrooten, C., Seefried, M., Su, G., Burdick, J., Chen, W., Abecasis, G., Cheung, V., Habier, D., Fernando, R., Dekkers, J., Zhang, Z., Druet, T., Villumsen, T., Janss, L., Wiggans, G., Sonstegard, T., VanRaden, P., Matukumalli, L., Schnabel, R., Taylor, J., Schenkel, F., Van Tassell, C., Meuwissen, T., Hayes, B., Goddard, M., VanRaden, P., Sargolzaei, M., Schenkel, F., Toosi, A., Fernando, R., Dekkers, J., Yang, J., Benyamin, B., McEvoy, B., 
Gordon, S., Henders, A., Nyholt, D., Madden, P., Heath, A., Martin, N., Montgomery, G., Henderson, C., Cole, J., VanRaden, P., VanRaden, P., Sullivan, P., Liu, Z.F.,

Seefried, Null, Reinhardt, F., Reents, R., Flaquer, A., Fischer, C., Wienker, T., Cole, J., VanRaden, P., O'Connell, J., Van Tassell, C., Sonstegard, T., Schnabel, R., Taylor, J., Wiggans, G., VanRaden, P., O'Connell, J., Wiggans, G., Weigel, K., Weigel, K., de los Campos, G., Vazquez, A., Van Tassell, C., Rosa, G., Gianola, D., O'Connell, J., VanRaden, P., Wiggans, G., Vanraden, P., Taylor, J., Bean, B., Marshall, C., Sullivan, J., Macciotta, N., Gaspa, G., Steri, R., Nicolazzi, E., Dimauro, C., Pieramati, C., Cappio-Borlino, A., Villa-Angulo, R., Matukumalli, L., Gill, C., Choi, J., Van Tassell, C., Grefenstette, J., 2011. Genomic evaluations with many more genotypes. Genet. Sel. Evol. 43, 10. http://dx.doi.org/10.1186/1297-9686-43-10.

Yáñez, J.M., Martinez, V., 2010. Genetic factors involved in resistance to infectious diseases in salmonids and their application in breeding programmes. Arch. Med. Vet. 42, $1-13$.

Yáñez, J.M., Bangera, R., Lhorente, J.P., Oyarzún, M., Neira, R., 2013. Quantitative genetic variation of resistance against Piscirickettsia salmonis in Atlantic salmon (Salmo salar). Aquaculture 414-415, 155-159.

Yáñez, J.M., Houston, R.D., Newman, S., 2014a. Genetics and genomics of disease resistance in salmonid species. Front. Genet. 5, 1-13. http://dx.doi.org/10.3389/fgene. 2014.00415.

Yáñez, J.M., Lhorente, J.P., Bassini, L.N., Oyarzún, M., Neira, R., Newman, S., 2014b. Genetic co-variation between resistance against both Caligus rogercresseyi and
Piscirickettsia salmonis, and body weight in Atlantic salmon (Salmo salar). Aquaculture 433, 295-298. http://dx.doi.org/10.1016/j.aquaculture.2014.06.026.

Yáñez, J.M., Newman, S., Houston, R.D., 2015. Genomics in aquaculture to better understand species biology and accelerate genetic progress. Front. Genet. 6, 1-3. http:// dx.doi.org/10.3389/fgene.2015.00128.

Yáñez, J.M., Naswa, S., López, M.E., Bassini, L., Correa, K., Gilbey, J., Bernatchez, L. Norris, A., Neira, R., Lhorente, J.P., Schnable, P.S., Newman, S., Mileham, A., Deeb, N., Di Genova, A., Maass, A., 2016. Genome-wide single nucleotide polymorphism (SNP) discovery in Atlantic salmon (Salmo salar): validation in wild and farmed American and European populations. Mol. Ecol. Resour. http://dx.doi.org/10.1111/ 1755-0998.12503. (n/a-n/a).

Yoshida, G.M., Lhorente, J.P., Carvalheiro, R., Yáñez, J.M., 2017. Bayesian genome-wide association analysis for body weight in farmed Atlantic salmon (Salmo salar L.). Anim. Genet. http://dx.doi.org/10.1111/age.12621.

Yoshida, G.M., Bangera, R., Carvalheiro, R., Correa, K., Figueroa, R., Lhorente, J.P., Yáñez, J.M., 2018. Genomic prediction accuracy for resistance against Piscirickettsia salmonis in farmed rainbow trout. G3 Genes Genomes Genet. http://dx.doi.org/10. 1534/g3.117.300499. (g3.300499.2017).

Zhang, Z., Druet, T., 2010. Marker imputation with low-density marker panels in Dutch Holstein cattle. J. Dairy Sci. 93, 5487-5494. http://dx.doi.org/10.3168/jds.20103501. 